\title{
Effectiveness and Safety of Tocilizumab: Postmarketing Surveillance of 7901 Patients with Rheumatoid Arthritis in Japan
}

\author{
Takao Koike, Masayoshi Harigai, Shigeko Inokuma, Naoki Ishiguro, Junnosuke Ryu, \\ Tsutomu Takeuchi, Syuji Takei, Yoshiya Tanaka, Yoko Sano, Hitomi Yaguramaki, \\ and Hisashi Yamanaka
}

\begin{abstract}
Objective. An all-patient postmarketing surveillance program was conducted to evaluate the safety and effectiveness of tocilizumab (TCZ) for rheumatoid arthritis (RA) in the real-world clinical setting in Japan.

Methods. Patients received $8 \mathrm{mg} / \mathrm{kg}$ TCZ every 4 weeks and were observed for 28 weeks. Data were collected on patient characteristics, and drug safety and effectiveness.

Results. A total of 7901 patients were enrolled. Percentages of total and serious adverse events (AE) were $43.9 \%$ and $9.6 \%$, respectively. The most common serious AE were infections (3.8\%). Logistic regression analysis identified the following risk factors for the development of serious infection: age $\geq 65$ years, disease duration $\geq 10$ years, previous or concurrent respiratory disease, and concomitant corticosteroid dose $>5 \mathrm{mg} /$ day (prednisolone equivalent). The incidence rate of serious infections in patients with $\geq 3$ risk factors was $11.2 \%$, compared with $1.2 \%$ for patients without risk factors. The Week 28 rates of 28-joint Disease Activity Score-erythrocyte sedimentation rate remission, Boolean remission, and European League Against Rheumatism (EULAR) Good Response were 47.6\%, $15.1 \%$, and $59.4 \%$, respectively. Contributing factors for effectiveness were body weight $\geq 40 \mathrm{~kg}$, less advanced RA, no previous biologics, no concomitant corticosteroids or nonsteroidal antiinflammatory drugs, and low disease activity at baseline. From the benefit-risk balance analysis, patients with a high probability of remission and a low probability of developing serious infection were most likely to have less advanced RA and to have not received biologics previously.

Conclusion. These data confirm the safety and effectiveness of TCZ in patients with RA in the real-world clinical setting in Japan and identify factors that contribute to the successful use of TCZ for RA. (First Release Nov 1 2013; J Rheumatol 2014;41:15-23; doi:10.3899/jrheum.130466)
\end{abstract}

Key Indexing Terms:

RHEUMATOID ARTHRITIS BIOLOGICAL PRODUCTS INTERLEUKINS

POSTMARKETING

$\begin{array}{ll}\text { BIOLOGICAL PRODUCTS } & \text { INTERLEUKINS } \\ \text { RISK FACTORS } & \text { BENEFIT RISK ASSESSMENT }\end{array}$

From the Sapporo Medical Center NTT EC, Sapporo; Department of Pharmacovigilance, Tokyo Medical and Dental University Graduate School of Medical and Dental Sciences, Tokyo; Department of Allergy and Rheumatic Disease, Japanese Red Cross Medical Center, Tokyo; Department of Orthopedic Surgery, Nagoya University Graduate School of Medicine, Aichi; Nihon University, Tokyo; Division of Rheumatology/Clinical Immunology, Department of Internal Medicine, School of Medicine, Keio University, Tokyo; School of Health Sciences, Faculty of Medicine, Kagoshima University, Kagoshima; The First Department of Internal Medicine, University of Occupational and Environmental Health, Kitakyushu; Pharmacovigilance Department, Chugai Pharmaceutical Co. Ltd., Tokyo; Tokyo Women's Medical University, Tokyo; Committee on Postmarketing Surveillance of the Japan College of Rheumatology, Tokyo, Japan.

Supported by Chugai Pharmaceutical Co. Ltd. T. Koike has received payment for lectures from Abbott, Astellas, Bristol Myers Squibb, Chugai, Eisai, Mitsubishi Tanabe Pharma, Pfizer, Santen, Takeda, Taisyo-Toyama, Teijin, and UCS. M. Harigai has received research grants, speaking fees, or honoraria from Abbott, Astellas Pharma, Bristol-Myers Squibb, Chugai, Eisai Pharmaceuticals, Janssen Pharmaceuticals, Mitsubishi Tanabe Pharma, Santen Pharmaceutical, Takeda Pharmaceuticals, UCB Japan, and Pfizer; and has received consultant fees from Abbott, Bristol-Myers Squibb, Chugai, and Janssen Pharmaceuticals. N. Ishiguro has received grants and payment for lectures from Abbott, Chugai,
Daiichi-Sankyo Pharmaceutical, Eisai, Mitsubishi Tanabe Pharma, Pfizer, and Takeda.T. Takeuchi has received research grants, travel funds, and payment for writing or reviewing a manuscript from Asahi Kasei Medical, Astra Zeneca, Bristol-Myers, Eli Lilly, Janssen Pharmaceutical, Mitsubishi Tanabe Pharma, and Novartis. S. Takei has received grants from Bristol-Myers Squibb, Chugai, Eisai, and Takeda. Y. Sano and $H$. Yaguramaki are employees of Chugai. H. Yamanaka has received grants and speaking fees from Chugai.

T. Koike, MD, Chief Executive, Sapporo Medical Center NTT EC, and Committee on Postmarketing Surveillance (PMS) of Japan College of Rheumatology; M. Harigai, MD, PhD, Professor, Department of Pharmacovigilance, Tokyo Medical and Dental University Graduate School of Medical and Dental Sciences, and Committee on PMS of Japan College of Rheumatology; S. Inokuma, MD, Director, Department of Allergy and Rheumatic Disease, Japanese Red Cross Medical Center, and Committee on PMS of Japan College of Rheumatology; N. Ishiguro, MD, PhD, Department of Orthopedic Surgery, Nagoya University Graduate School of Medicine, and Committee on PMS of Japan College of Rheumatology; J. Ryu, MD, Nihon University, and Committee on PMS of Japan College of Rheumatology; T. Takeuchi, MD, PhD, Professor, Division of Rheumatology/Clinical Immunology, Department of Internal Medicine, School of Medicine, Keio University, and Committee on PMS of Japan College of Rheumatology; S. Takei, MD, PhD, Professor, School of Health Sciences, Faculty of Medicine, Kagoshima University, and 
Committee on PMS of Japan College of Rheumatology; Y. Tanaka, MD, PhD, Professor, The First Department of Internal Medicine, University of Occupational and Environmental Health, and Committee on PMS of Japan College of Rheumatology; Y. Sano, BS, Pharmacovigilance Department, Chugai Pharmaceutical Co. Ltd.; H. Yaguramaki, BS, Pharmacovigilance Department, Chugai Pharmaceutical Co. Ltd.; H. Yamanaka, MD, Tokyo Women's Medical University, and Committee on PMS of Japan College of Rheumatology.

Address correspondence to Dr. T. Koike, Sapporo Medical Center NTT EC, S 1, W 15, Chuo Ku, Sapporo, Hokkaido, 060 0061, Japan.

E-mail:tkoike@med.hokudai.ac.jp.

Full Release Article. For details see Reprints/Permissions at jrheum.org Accepted for publication August 28, 2013.

Tocilizumab (TCZ) received marketing approval as an antirheumatic agent in Japan in 2008, in the European Union in 2009, and in the United States in 2010. As a condition of approval, the Japanese health authority required that Chugai Pharmaceutical Co. Ltd. conduct an all-patient postmarketing surveillance (PMS) to investigate the safety and effectiveness of TCZ in the real-world clinical setting. Our report details the final results of the PMS using data from all 7901 patients who were enrolled in the surveillance program and had case report forms collected. We also conducted a benefit-risk analysis of TCZ treatment to determine how to obtain the best possible clinical outcomes for patients with rheumatoid arthritis (RA).

\section{MATERIALS AND METHODS}

Patients. All patients with RA in Japan who started treatment with TCZ between April 2008 and August 2010 were enrolled in our study and monitored during the surveillance period. Interim results covering 3881 patients with RA were previously published ${ }^{1}$. In accordance with the Japanese package insert, TCZ was administered to patients who had an inadequate response to at least 1 antirheumatic agent. Further, consistent with the Japan College of Rheumatology Guidelines for using TCZ, it was recommended that patients meet all the following criteria before starting TCZ treatment: $\geq 6$ tender joints ( 68 joints), $\geq 6$ swollen joints ( 66 joints), erythrocyte sedimentation rate $(\mathrm{ESR}) \geq 28 \mathrm{~mm} / \mathrm{h}$ or C-reactive protein (CRP) $\geq 2.0 \mathrm{mg} / \mathrm{dl}$, white blood cell count $\geq 4000 / \mathrm{mm}^{3}$, lymphocyte count $\geq 1000 / \mathrm{mm}^{3}$, and serum $\beta$-D-glucan-negative. Before TCZ treatment was initiated, all patients were required to undergo screening for tuberculosis by means of a chest radiograph, a tuberculin test, and an interview ${ }^{2}$.

Protocol. Our PMS study was a single-arm observational study that began in April 2008. The data were evaluated by Chugai Pharmaceutical Co. Ltd., the manufacturer of TCZ, in collaboration with the Committee on PMS of the Japan College of Rheumatology. Patient registration, which occurred before starting TCZ treatment, was centrally controlled. Patients received 8 $\mathrm{mg} / \mathrm{kg}$ TCZ intravenously once every 4 weeks. During the TCZ treatment period, there were no restrictions on the use of concomitant disease-modifying antirheumatic drugs (DMARD) such as methotrexate (MTX) or corticosteroids. Data were collected using case report forms, and patients were observed for 28 weeks after TCZ was initiated or within 4 weeks of the last TCZ infusion. All events that occurred during the 28 weeks after the first TCZ infusion were included in the safety analysis. The effectiveness of TCZ treatment was analyzed at 28 weeks.

Statistical analysis. Adverse events (AE) were coded using the Medical Dictionary for Regulatory Activities (vol 13.1). Risk factors for serious infection and readouts of effectiveness [disease activity score based on 28 joints-erythrocyte sedimentation rate (DAS28-ESR) remission, Boolean remission, and European League Against Rheumatism (EULAR) Good Response] ${ }^{3}$ were investigated using multivariate logistic regression analyses after the selection of variables based on the results of univariate logistic regression analyses and clinical significance. The standardized mortality ratio (SMR) was calculated using the 2009 database for mortality rates in the Japanese general population ${ }^{4}$. The last observation carried forward (LOCF) method was used for missing data (other than baseline values) needed to assess effectiveness. Patients without either baseline or Week 28 DAS28-ESR values were excluded from the effectiveness analysis model. For patients who transferred between medical institutions during the all-patient surveillance period, data from case report forms were consolidated whenever possible and handled as a single case report. Statistical significance in our study was set at $\mathrm{p}<0.05$.

To assess the benefit-risk balance of treatment with TCZ, predicted probabilities $(0-1)$ of developing serious infection were plotted against predicted probabilities $(0-1)$ of achieving Boolean-based remission at Week 28 using the LOCF method. This distribution of predicted probabilities was derived from both the logistic model used for serious infections and the logistic model used for Boolean-based remission.

\section{RESULTS}

Patient demographics. For this final report, 7901 patients with RA were analyzed. The cumulative exposure to TCZ was 3831.8 patient-years (PY) and the mean observation period was 25.3 weeks (SD 6.4 weeks). A total of 6522 patients $(82.5 \%)$ completed the 28 -week observation period. Of the 1302 patients $(16.5 \%)$ who discontinued treatment with TCZ, the primary reason for discontinuation was AE for 606 patients (46.5\%), insufficient response for 350 patients (26.9\%), achievement of treatment goals for 59 patients (4.5\%), and financial or other reasons for 287 patients $(22.0 \%)$. A total of 77 patients were lost to followup. Prior to treatment with TCZ, 4964 patients $(62.8 \%)$ had received biologics: 3484 patients $(44.1 \%)$ had used 1 prior biologic, 1368 patients (17.3\%) had used 2 prior biologics, and 112 patients $(1.4 \%$ ) had used 3 prior biologics (Table 1). A total of 2064 patients $(26.1 \%)$ had previous or concurrent respiratory disease including interstitial lung disease, obstructive lung disease, and respiratory infection. A total of 4405 patients $(55.8 \%)$ had received concomitant MTX. The mean dose of MTX was $7.0 \mathrm{mg} /$ week.

Safety. Overall, during the 28-week observation period, there were $6460 \mathrm{AE}$ in 3468 patients $(43.9 \%, 168.6$ events/100 $\mathrm{PY}$ ) and 1050 serious $\mathrm{AE}$ in 762 patients $(9.6 \%, 27.4$ events/100 PY). The most common serious AE were infections [343 events in 298 patients (3.8\%, 9.0 events/100 PY)] and abnormal laboratory test values [ 100 events in 80 patients $(1.0 \%, 2.6$ events/100 PY)]. Respiratory infections were the most common type of serious infection [143 events in 134 patients (1.7\%, 3.7 events/100 PY)], and of those, pneumonia was the most frequent [97 events in 90 patients $(1.1 \%, 2.5$ events/100 PY)]. Five patients developed tuberculosis (4 pulmonary and 1 peritoneal); none of them had a history of it. A total of 35 fatalities were reported. The most common cause of death was infection in 9 patients, followed by cardiovascular disorder in 8 patients, respiratory disorder in 7, cerebrovascular disorder in 4, malignant tumor in 3 , and other causes in 4. The SMR in this study, in comparison with the general Japanese population, was 1.15 (95\% CI 0.83-1.61). 
Table 1. Characteristics of patients with rheumatoid arthritis (RA) participating in the all-patient postmarketing surveillance of tocilizumab (TCZ) in Japan.

\begin{tabular}{|c|c|}
\hline Characteristics & $\begin{array}{c}\mathrm{TCZ}, \mathrm{n}=7901 \\
3831.8 \mathrm{PY} \\
25.3 \pm 6.4 \text { Weeks }\end{array}$ \\
\hline \multicolumn{2}{|l|}{ Demographics } \\
\hline Female, n $(\%)$ & $6445(81.6)$ \\
\hline Age, yrs, mean (SD) & $58.7(12.9)$ \\
\hline Median, range & $60.0(15.0-91.0)$ \\
\hline$\geq 70, \mathrm{n}(\%)$ & 1635 (20.7) \\
\hline Body weight, kg, mean (SD) & $53.3(10.2)$ \\
\hline Body weight < 40 kg, n (\%) & $426(5.4)$ \\
\hline Disease duration, yrs, mean (SD) & $10.4(9.2)$ \\
\hline Median, range & $7.8(0.0-61.9)$ \\
\hline History of tuberculosis, n (\%) & $360(4.6)$ \\
\hline \multicolumn{2}{|l|}{ History of comorbidities, n (\%) } \\
\hline Respiratory disease & $2064(26.1)$ \\
\hline Interstitial lung disease & $914(11.6)$ \\
\hline Cardiac disorder & $523(6.6)$ \\
\hline Hepatic disorder & $562(7.1)$ \\
\hline Renal disorder & $482(6.1)$ \\
\hline Diabetes mellitus & $796(10.1)$ \\
\hline \multicolumn{2}{|l|}{ Clinical characteristics } \\
\hline \multicolumn{2}{|l|}{ Steinbrocker radiographic stage, n (\%) } \\
\hline I & $635(8.0)$ \\
\hline II & $2145(27.1)$ \\
\hline III & $2583(32.7)$ \\
\hline IV & $2532(32.0)$ \\
\hline \multicolumn{2}{|l|}{ Steinbrocker functional class, n (\%) } \\
\hline 1 & $943(11.9)$ \\
\hline 2 & $4884(61.8)$ \\
\hline 3 & $1994(25.2)$ \\
\hline 4 & $71(0.9)$ \\
\hline Baseline DAS28-ESR, mean (SD) & $5.3(1.4)$ \\
\hline Previous use of biologics, n (\%) & $4964(62.8)$ \\
\hline 1 drug & $3484(44.1)$ \\
\hline 2 drugs & $1368(17.3)$ \\
\hline 3 drugs & $112(1.4)$ \\
\hline Concomitant DMARD use ${ }^{\mathrm{a}}, \mathrm{n}(\%)$ & $5724(72.4)$ \\
\hline Concomitant $\mathrm{MTX}^{\mathrm{a}}, \mathrm{n}(\%)$ & $4405(55.8)$ \\
\hline MTX dose, mg/week, mean (SD) & $7.0(2.4)$ \\
\hline MTX dose, mg/week, min-max & $1-20$ \\
\hline Concomitant oral corticosteroid use ${ }^{\mathrm{a}}, \mathrm{n}(\%)$ & $5843(74.0)$ \\
\hline Corticosteroid dose, mg/day, mean (SD) & $5.3(3.3)$ \\
\hline Corticosteroid dose, mg/day, min-max & $0.1-60$ \\
\hline
\end{tabular}

a Concomitant use at any timepoint during the observation period, including baseline. DAS28-ESR: Disease Activity Score based on 28-joint-erythrocyte sedimentation rate; DMARD: disease-modifying antirheumatic drug; MTX: methotrexate; PY: patient-years; RA: rheumatoid arthritis; TCZ: tocilizumab.

AE of special interest. Because serious infections were the most common serious AE reported during the TCZ PMS, a multivariate logistic regression analysis (stepwise method) was conducted to identify risk factors. This analysis identified advanced age ( $\geq 65 \mathrm{yrs}$ ), longer disease duration ( $\geq 10 \mathrm{yrs}$ ), previous or concurrent respiratory disease, and a mean concomitant corticosteroid dose $>5 \mathrm{mg}$ /day (prednisolone equivalent) as factors that can increase the risk for serious infections in patients with RA during treatment with TCZ (Figure 1A). The cumulative incidence of serious infections stratified by the number of present risk factors demonstrated that patients with 1 risk factor (cumulative incidence: $3.0 \%$ ), 2 risk factors (cumulative incidence: $5.2 \%$ ), or at least 3 risk factors (cumulative incidence: $11.2 \%$ ) had a significantly higher cumulative incidence of serious infections than did patients with no risk factors [cumulative incidence: 1.2\%; p < 0.001 (log-rank test); Figure 1B]. The incidence rate of serious infection for patients with concomitant MTX was lower than that for patients without concomitant MTX by simple regression analyses. Concomitant use of MTX was not identified as a risk factor in a multivariate logistic regression analysis (data not shown). Pulmonary tuberculosis was reported in 4 patients. Three patients were negative for TB at baseline screening, and 1 had $1+$ for the tuberculin test. All 4 patients had previously used other biologics.

Malignancies, including nonmelanoma skin cancer, were reported in 39 patients $(0.5 \%)$, but no trend in cancer type has been observed to date (Table 2).

Anaphylaxis was reported in 10 patients $(0.1 \%, 0.3$ events/100 PY; Table 2), and TCZ treatment was immediately discontinued in 9 of those patients. In the remaining patient, TCZ treatment was suspended but resumed at a slower rate after recovery from anaphylaxis. All 10 patients were treated with drugs, including antihistamines and corticosteroids, and recovered or improved on the day of anaphylaxis onset. Eight of the 10 patients received concomitant disease-modifying antirheumatic drugs (DMARD). In 8 of the patients, anaphylaxis occurred within the first $3 \mathrm{TCZ}$ infusions.

Gastrointestinal (GI) perforation was reported in 13 patients $(0.2 \%, 0.4$ events/100 PY; Table 2$)$. In 11 of the 13 patients, the perforation was in the lower GI tract. Of those 13 patients, 7 fully recovered, 5 improved, and 1 resolved with sequelae (colostomy). No deaths were reported from GI perforation. Twelve of the 13 patients used concomitant corticosteroids. None of the 13 patients previously had diverticulitis.

Serious hepatobiliary disorders were reported in 28 patients $(0.4 \%, 0.8$ events/100 PY). Of those 28 patients, 15 recovered, 6 improved, 3 did not recover, 2 died, and 2 had unknown outcomes. One of the fatal cases had lymphoma, which was determined to be the main cause of death. The other case had hepatic cirrhosis and bile duct cancer at baseline, the causes of death. Fifty-two patients had a history of hepatitis B virus or were carriers, and 76 patients had a history of hepatitis $\mathrm{C}$ virus or were carriers. None of those patients experienced virus reactivation, with or without hepatitis.

Interstitial lung disease (ILD) was reported in 38 patients $(0.5 \%, 1.0$ event/100 PY), and 22 of them had a concurrent or medical history of ILD at baseline. Twenty-four of the 38 
A.

\begin{tabular}{|c|c|c|c|c|}
\hline & $\begin{array}{l}\text { No. of Patients with Sis/ } \\
\text { No. of Patients }(\%)\end{array}$ & \begin{tabular}{|l} 
Odds \\
Ratio
\end{tabular} & $95 \% \mathrm{Cl}$ & $p$ Value \\
\hline Total & $298 / 7901(3.77)$ & & & \\
\hline $\begin{array}{l}\text { Age } \\
<65 \text { years } \\
\geq 65 \text { years } \\
\text { Unknown }\end{array}$ & $\begin{array}{l}143 / 4993(2.86) \\
155 / 2906(5.33) \\
0 / 2(0)\end{array}$ & 1.536 & 1.017 to 2.319 & 0.0415 \\
\hline $\begin{array}{l}\text { Duration of disease } \\
<10 \text { years } \\
\geq 10 \text { years } \\
\text { Unknown }\end{array}$ & $\begin{array}{l}139 / 4460(3.12) \\
144 / 2972(4.85) \\
15 / 469(3.20)\end{array}$ & 1.791 & 1.190 to 2.695 & 0.0052 \\
\hline $\begin{array}{l}\text { Respiratory disease } \\
\text { (previous or concurrent) } \\
\text { No respiratory disease }\end{array}$ & $\begin{array}{l}141 / 2064(6.83) \\
157 / 5837(2.69)\end{array}$ & 1.932 & 1.275 to 2.926 & 0.0019 \\
\hline $\begin{array}{l}\text { Concomitant corticosteroid } \\
\text { use (oral only) } \\
0 \mathrm{mg} / \text { day } \\
>0 \text { to } \leq 5 \mathrm{mg} / \text { day } \\
>5 \mathrm{mg} / \text { day }\end{array}$ & $\begin{array}{l}45 / 2058(2.19) \\
119 / 3873(3.07) \\
134 / 1970(6.80)\end{array}$ & $\begin{array}{l}0.962 \\
2.791\end{array}$ & $\begin{array}{l}0.532 \text { to } 1.740 \\
1.581 \text { to } 4.921\end{array}$ & $\begin{array}{l}0.8987 \\
0.0004\end{array}$ \\
\hline
\end{tabular}

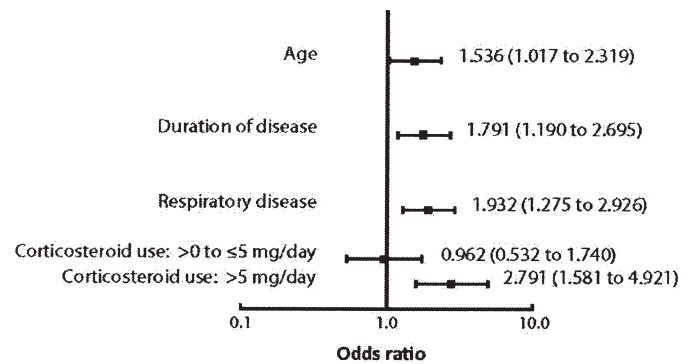

B.

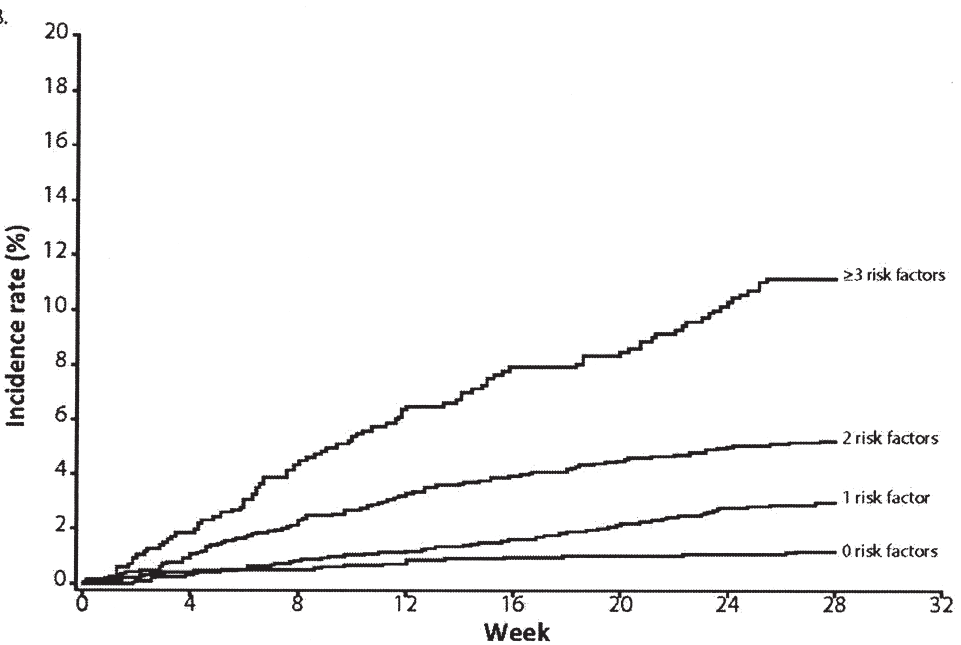

\begin{tabular}{|l|c|c|c|c|}
\hline & ORisk factors & 1Risk factor & 2 Risk factors & 23Risk factors \\
\hline Patients(n) & $19 / 5$ & 2931 & 2120 & $8 / 5$ \\
\hline Cumulative incidence at week 28(\%) & 1.18 & 2.98 & 5.24 & 11.15 \\
\hline
\end{tabular}

\begin{tabular}{|l|c|c|c|}
\hline Log-rank test & $\chi^{2}$ & $d f$ & $p$ Value \\
\hline Trisk factorvs 0 riskfactors & 15.3133 & 1 & $<0.001$ \\
\hline 2 riskfactors vs 0 riskfactors & 49.9071 & 1 & $<0.001$ \\
\hline 2 risk factors vs 1 riskfactor & 17.0593 & 1 & $<0.001$ \\
\hline z3riskfactors vs 0 riskfactors & 139.6476 & 1 & $<0.001$ \\
\hline$\geq 3$ risk factors vs 1 risk factor & 94.1461 & 1 & $<0.001$ \\
\hline
\end{tabular}

Figure 1. Risk factors for serious infections. A. Factors that can increase the risk for serious infections. B. Incidence rates for serious infections based on the number of patient risk factors. Explanatory variables examined: sex, age, body weight, duration of disease, Steinbrocker class, Steinbrocker stage, previous or concurrent respiratory disease, previous or concurrent renal impairment, previous infection, concurrent infection, concurrent diabetes mellitus, smoking, concomitant methotrexate, concomitant corticosteroids, lymphocyte count at baseline (per $\left.\mathrm{mm}^{3}\right)$, and immunoglobulin $\mathrm{G}$ at baseline $(\mathrm{mg} / \mathrm{dl})$. Sis: serious infections; Df: degrees of freedom. 


\begin{tabular}{|c|c|c|c|c|c|c|}
\hline & $\mathrm{N}$ & $\begin{array}{l}\text { Serious AE } \\
\text { Incidence } \\
\text { Rate }(\%)\end{array}$ & $\begin{array}{l}\text { Events/ } \\
100 \mathrm{PY}\end{array}$ & $\mathrm{N}$ & $\begin{array}{l}\text { Total AE } \\
\text { Incidence } \\
\text { Rate }(\%)\end{array}$ & $\begin{array}{l}\text { Events/ } \\
100 \mathrm{PY}\end{array}$ \\
\hline $\mathrm{AE}$ & 762 & 9.64 & 27.40 & 3468 & 43.89 & 168.59 \\
\hline Infection & 298 & 3.77 & 8.95 & 874 & 11.06 & 27.98 \\
\hline Respiratory infection & 134 & 1.70 & 3.73 & 462 & 5.85 & 14.07 \\
\hline Pneumonia & 90 & 1.14 & 2.53 & 121 & 1.53 & 3.44 \\
\hline Pulmonary TB & 4 & 0.05 & 0.10 & 4 & 0.05 & 0.10 \\
\hline Nontuberculous mycobacteriosis & 17 & 0.22 & 0.44 & 17 & 0.22 & 0.44 \\
\hline Pneumocyctis pneumonia & 13 & 0.16 & 0.34 & 14 & 0.18 & 0.37 \\
\hline Urinary tract infection & 20 & 0.25 & 0.57 & 60 & 0.76 & 1.64 \\
\hline GI infection & 45 & 0.57 & 1.33 & 103 & 1.30 & 2.98 \\
\hline Skin infection & 70 & 0.89 & 1.85 & 238 & 3.01 & 6.52 \\
\hline Herpes zoster & 18 & 0.23 & 0.47 & 86 & 1.09 & 2.24 \\
\hline Cellulitis & 31 & 0.39 & 0.81 & 58 & 0.73 & 1.54 \\
\hline Bone and joint infection & 27 & 0.34 & 0.73 & 29 & 0.37 & 0.84 \\
\hline Other infection & 26 & 0.33 & 0.73 & 69 & 0.87 & 1.93 \\
\hline Cardiac dysfunction & 38 & 0.48 & 1.07 & 59 & 0.75 & 1.62 \\
\hline Ischemic heart disease & 16 & 0.20 & 0.42 & 18 & 0.23 & 0.47 \\
\hline Cardiac failure & 11 & 0.14 & 0.31 & 11 & 0.14 & 0.31 \\
\hline GI perforation & 13 & 0.16 & 0.37 & 13 & 0.16 & 0.37 \\
\hline Malignancy & 38 & 0.48 & 0.99 & 39 & 0.49 & 1.02 \\
\hline Lymphoma & 7 & 0.08 & 1.83 & 7 & 0.08 & 1.83 \\
\hline Nonhematopoietic malignancy & 31 & 0.39 & 0.81 & 32 & 0.41 & 0.84 \\
\hline Infusion reaction & 22 & 0.28 & 0.68 & 278 & 3.52 & 12.21 \\
\hline Anaphylaxis & 10 & 0.13 & 0.26 & 10 & 0.13 & 0.26 \\
\hline Lipid-related test abnormality & 6 & 0.08 & 0.18 & 721 & 9.13 & 20.83 \\
\hline ILD & 38 & 0.48 & 0.99 & 38 & 0.48 & 0.99 \\
\hline Hepatobiliary disorders & 28 & 0.35 & 0.84 & 775 & 9.81 & 23.88 \\
\hline Death & - & - & - & 35 & 0.44 & 0.91 \\
\hline
\end{tabular}

PY: patient-years; TB: tuberculosis; GI: gastrointestinal; ILD: interstitial lung disease.

patients had previously received other biologics. Of the 38 patients, 11 recovered, 14 improved, 2 did not recover, 1 recovered with sequelae, 7 died, and 3 had an unknown outcome. As identified by multivariate logistic regression analysis, the risk factors for ILD were advanced age ( $\geq 65$ years) and previous or concurrent ILD at baseline.

Lipid abnormalities were also reported. An increase in total serum cholesterol to $\geq 300 \mathrm{mg} / \mathrm{dl}$ was detected in 187 patients $(2.4 \%)$, and an increase in triglycerides to $\geq 300$ $\mathrm{mg} / \mathrm{ml}$ was detected in 99 patients $(1.3 \%)$ at 1 or more measurement points during the surveillance period. No serious cardiovascular events were reported in those patients. Serious ischemic heart disease was reported in 16 patients $(0.20 \%)$. Of the 16 patients, 7 recovered, 4 improved, 1 recovered with sequelae, and 4 died. Heart failure was reported in 11 patients $(0.14 \%)$. Of the 11 patients, 3 recovered, 3 improved, and 5 died.

Effectiveness. The DAS28-ESR remission rate (DAS28-ESR <2.6) and EULAR Good Response rate for this PMS study at Week 28 were $47.6 \%$ (2260 of 4745 patients) and $59.4 \%$ (2817 of 4745 patients), respectively. Further, at 28 weeks, the Boolean-based remission rate was 15.1\% (894 of 5904 patients). The mean (SD) DAS28-ESR decreased from 5.5
(1.3) at baseline to 2.9 (1.5) at Week 28, with a trend of improvement detectable in all individual DAS28-ESR components, i.e., the mean ESR decreased from 54.4 (32.6) to $12.6(17.0) \mathrm{mm} / \mathrm{h}$, the mean tender joint count (28 joints) decreased from 7.7 (6.7) to 3.2 (4.8), the mean swollen joint count (28 joints) decreased from 7.1 (5.8) to 2.7 (3.9), and the mean Patient Global Assessment decreased from 56.0 (24.3) to 31.3 (24.1). Additionally, the mean CRP level decreased from 2.9 (3.0) to $0.5(1.7) \mathrm{mg} / \mathrm{dl}$.

Multivariate logistic regression analyses (full model) were conducted of the factors that affect achievement of DAS28 remission, Boolean remission, and EULAR Good Response rate. The factors that were confirmed to improve TCZ effectiveness by all 3 assessment methods were higher body weight ( $\geq 40 \mathrm{~kg}$ ), less advanced RA (Steinbrocker stage I+II or class $1+2$ ), no previous administration of biologics, no concomitant corticosteroids, no concomitant nonsteroidal antiinflammatory drugs (NSAID), and lower disease activity at baseline (Table 3). Concomitant use of MTX contributed to achievement of DAS28 remission and EULAR Good Response, but not Boolean remission. The dosage of MTX did not affect achievement of each index by simple regression analyses (data not shown). 
Table 3. Factors influencing tocilizumab effectiveness in 3 assessment methods: DAS28-ESR remission, EULAR Good Response, and Boolean remission (a full-model multivariate logistic regression analysis). Shaded factors have been shown to support the achievement of DAS28-ESR remission, EULAR Good Response, and Boolean-based remission.

\begin{tabular}{|c|c|c|c|c|c|c|c|}
\hline & & \multicolumn{2}{|c|}{ DAS28-ESR Remission } & \multicolumn{2}{|c|}{ EULAR Good Response } & \multicolumn{2}{|c|}{ Boolean Remission } \\
\hline & & OR $(95 \% \mathrm{CI})$ & $\mathrm{p}$ & OR $(95 \% \mathrm{CI})$ & $\mathrm{p}$ & OR $(95 \% \mathrm{CI})$ & $\mathrm{p}$ \\
\hline Sex & Female vs male & $0.74(0.625-0.877)$ & 0.0005 & $0.856(0.725-1.012)$ & 0.0681 & $1.047(0.841-1.303)$ & 0.6825 \\
\hline Age & Per 10-yr increase & $0.874(0.829-0.921)$ & $<0.0001$ & $0.896(0.851-0.944)$ & $<0.0001$ & $0.957(0.897-1.022)$ & 0.1933 \\
\hline Body weight & $\geq 40 \mathrm{vs}<40 \mathrm{~kg}$ & $1.360(1.006-1.838)$ & 0.0453 & $1.347(1.019-1.780)$ & 0.0363 & $1.801(1.089-2.978)$ & 0.0219 \\
\hline \multirow[t]{2}{*}{ Duration of disease } & $2-10$ vs $<2$ yrs & $0.974(0.795-1.194)$ & 0.8008 & $0.847(0.690-1.040)$ & 0.1136 & $0.935(0.737-1.185)$ & 0.5785 \\
\hline & $\geq 10$ vs $<2$ yrs & $0.847(0.673-1.066)$ & 0.1562 & $0.747(0.594-0.940)$ & 0.0127 & $0.610(0.458-0.814)$ & 0.0008 \\
\hline Steinbrocker stage & $\mathrm{III}+\mathrm{IV}$ vs I + II & $0.722(0.615-0.847)$ & $<0.0001$ & $0.771(0.658-0.903)$ & 0.0013 & $0.736(0.601-0.901)$ & 0.0030 \\
\hline Steinbrocker class & $3+4$ vs $1+2$ & $0.652(0.557-0.765)$ & $<0.0001$ & $0.709(0.611-0.823)$ & $<0.0001$ & $0.630(0.490-0.809)$ & 0.0003 \\
\hline \multirow[t]{2}{*}{ Previous use of biologics } & 1 agent vs none & $0.621(0.537-0.719)$ & $<0.0001$ & $0.669(0.579-0.774)$ & $<0.0001$ & $0.615(0.512-0.739)$ & $<0.0001$ \\
\hline & 2 agents vs none & $0.494(0.409-0.596)$ & $<0.0001$ & $0.566(0.472-0.679)$ & $<0.0001$ & $0.407(0.310-0.536)$ & $<0.0001$ \\
\hline $\begin{array}{l}\text { MTX use (concomitant } \\
\quad \operatorname{drug}^{\text {a) }}\end{array}$ & Present vs absent & $1.158(1.013-1.323)$ & 0.0314 & $1.148(1.008-1.308)$ & 0.0372 & $0.903(0.759-1.075)$ & 0.2507 \\
\hline \multirow{2}{*}{$\begin{array}{l}\text { Corticosteroid use } \\
\quad\left(\text { concomitant drug }{ }^{\mathrm{a}}\right)\end{array}$} & $0-5 \mathrm{mg} /$ day $^{\mathrm{b}}$ vs none & $0.815(0.697-0.952)$ & 0.0099 & $0.932(0.798-1.088)$ & 0.3702 & $0.679(0.562-0.819)$ & $<0.0001$ \\
\hline & $>5 \mathrm{mg} /$ day $^{\mathrm{b}}$ vs none & $0.564(0.470-0.678)$ & $<0.0001$ & $0.641(0.536-0.766)$ & $<0.0001$ & $0.412(0.320-0.530)$ & $<0.0001$ \\
\hline $\begin{array}{l}\text { NSAID use } \\
\quad(\text { concomitant drug })\end{array}$ & Present vs absent & $0.865(0.757-0.988)$ & 0.0325 & $0.786(0.689-0.896)$ & 0.0003 & $0.692(0.584-0.820)$ & $<0.0001$ \\
\hline $\begin{array}{l}\text { DAS28-ESR } \\
\text { (at baseline) }\end{array}$ & Per 1-pt increase & $0.628(0.595-0.663)$ & $<0.0001$ & $0.794(0.755-0.835)$ & $<0.0001$ & $0.745(0.696-0.796)$ & $<0.0001$ \\
\hline
\end{tabular}

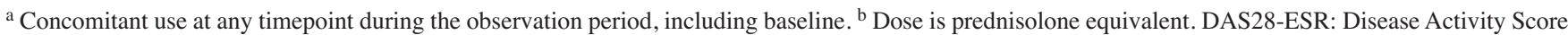
based on 28-joint-erythrocyte sedimentation rate; EULAR: European League Against Rheumatism; MTX: methotrexate; NSAID: nonsteroidal antiinflammatory drug.

Benefit-risk balance. To assess the benefit-risk balance of treatment with TCZ, predicted probabilities of developing serious infection were plotted against predicted probabilities of achieving Boolean-based remission and divided into 9 areas (Figure 2, areas A-I). In Figure 2, the patients in area A had a predicted $45.4 \%$ or higher probability of achieving
Boolean remission ( 3 times the detected Boolean remission rate of $15.1 \%$ ) and a $<3.8 \%$ (equal to the detected incidence) probability of developing serious infection. The patients in area I had a predicted $15.1 \%$ (equal to the detected incidence) or lower probability of achieving Boolean remission and a $7.5 \%$ or higher probability of

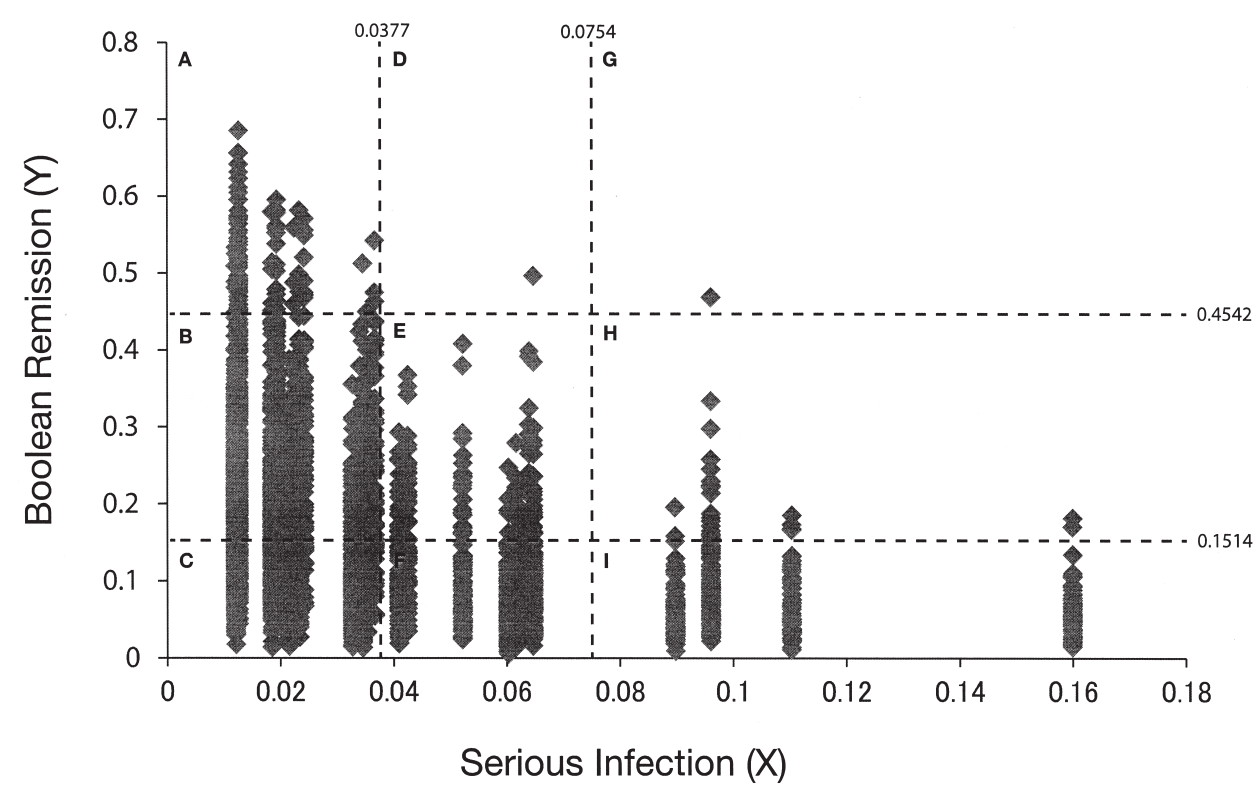

Figure 2. Benefit-risk balance. Predicted probabilities of developing serious infection versus predicted probabilities of achieving Boolean-based remission. Patients were divided into 9 areas (A-I). Numbers of patients in each area were 90 for A, 1628 for B, 1742 for $\mathrm{C}, 1$ for D, 144 for $\mathrm{E}, 635$ for $\mathrm{F}, 1$ for G, 28 for $\mathrm{H}$, and 335 for I. Functions: Area $\mathrm{A}=\mathrm{Y} \geq 0.4542$ and $\mathrm{X}<0.0377$; Area $\mathrm{I}=\mathrm{Y}<0.1514$ and $\mathrm{X} \geq 0.0754$. 
developing serious infection ( 2 times the detected serious infection incidence of $3.8 \%$ ). Therefore, higher predicted probabilities of achieving Boolean-based remission tended to be associated with lower predicted probabilities of developing serious infection (Figure 2, area A). Likewise, higher predicted probabilities of developing serious infection tended to be associated with lower predicted probabilities of achieving Boolean-based remission (Figure 2, area I).

Additionally, the background characteristics of these 2 patient groups (Figure 2, areas A and I) were compared. Compared with patients in area I, patients in area A were a mean of 16 years younger, had a mean disease duration period 11 years shorter, were more likely to have less advanced RA (Steinbrocker stage and Steinbrocker class), were less likely to have respiratory, cardiac, and renal comorbidities, were more likely to use concomitant MTX, were less likely to use concomitant corticosteroids, were less likely to have had previous biological therapy, and had lower DAS28-ESR at baseline (Table 4).

\section{DISCUSSION}

The safety and effectiveness profiles of TCZ reported here are consistent with the results of the interim analysis of this study ${ }^{1}$. The most common AE and SAE reported in this analysis were infections. The incidence rate of serious infections was higher in our report (9.1/100 PY) than in the TCZ clinical study in Japan $(6.2 / 100 \mathrm{PY})^{5}$ or in other TCZ global clinical studies $6,7,8,9,10,11,12$. In this PMS, all patients were enrolled, including those who had risk factors for serious infections, and all $\mathrm{AE}$ were monitored after initiating treatment. In the clinical trials, on the other hand, although the incidence rate of reported $\mathrm{AE}$ was accurate because all $\mathrm{AE}$ were recorded, patients were excluded for a number of conditions, including risk factors for serious infection. These factors may result in differences between this PMS and clinical studies for the incidence rates of serious infections. Further, the SMR for this study $(1.15 ; 95 \%$ CI 0.83-1.61) did not exceed that reported in the Institute of Rheumatology, Rheumatoid Arthritis (IORRA) Japanese RA cohort study, in which the SMR range was $1.46-1.90^{4}$. The most common cause of death was infection, followed by cardiovascular disorder and respiratory disease, whereas in the IORRA study the most common cause of death was malignancy. This difference may have been caused by the differences in the observation period between our study and the IORRA study ${ }^{4}$.

Table 4. Benefit-risk analysis.

\begin{tabular}{|c|c|c|c|}
\hline & $\begin{array}{c}\text { Area A, } \\
n=90\end{array}$ & $\begin{array}{c}\text { Area I, } \\
\mathrm{n}=335\end{array}$ & $\mathrm{p}$ \\
\hline Sex, female, n $(\%)$ & $19(21.11)$ & $98(29.25)$ & $0.125^{\mathrm{a}}$ \\
\hline Weight, kg, mean (SD) & $55.4(9.6)$ & $52.3(10.7)$ & $0.014^{\mathrm{b}}$ \\
\hline Age, yrs, mean (SD) & $51.7(14.8)$ & $68.1(8.2)$ & $<0.001^{\mathrm{b}}$ \\
\hline Duration of illness, yrs, mean (SD) & $3.1(3.8)$ & $13.9(9.5)$ & $<0.001^{\mathrm{b}}$ \\
\hline \multicolumn{4}{|l|}{ Disease stage by Steinbrocker, n (\%) } \\
\hline I & $41(45.56)$ & $10(2.99)$ & \multirow[t]{4}{*}{$<0.001^{\mathrm{a}}$} \\
\hline II & $41(45.56)$ & $60(17.91)$ & \\
\hline III & $5(5.56)$ & $110(32.84)$ & \\
\hline IV & $3(3.33)$ & $155(46.27)$ & \\
\hline \multicolumn{4}{|l|}{ Function class by Steinbrocker, n (\%) } \\
\hline 1 & $50(55.56)$ & $15(4.48)$ & \multirow[t]{4}{*}{$<0.001^{\mathrm{a}}$} \\
\hline 2 & $40(44.44)$ & $177(52.84)$ & \\
\hline 3 & 0 & $136(40.60)$ & \\
\hline 4 & 0 & $7(2.09)$ & \\
\hline \multicolumn{4}{|l|}{ Comorbidities } \\
\hline Any comorbidities & $37(41.11)$ & $318(94.93)$ & $<0.001^{\mathrm{a}}$ \\
\hline Respiratory disease & $9(10.00)$ & $173(51.64)$ & $<0.001^{\mathrm{a}}$ \\
\hline Cardiac functional disorders & $2(2.22)$ & $47(14.03)$ & $0.002^{\mathrm{a}}$ \\
\hline Liver disorders & $8(8.89)$ & $23(6.87)$ & $0.512^{\mathrm{a}}$ \\
\hline Renal dysfunction & $1(1.11)$ & $23(6.87)$ & $0.036^{\mathrm{a}}$ \\
\hline \multicolumn{4}{|l|}{ Concomitant drug use ${ }^{c}$} \\
\hline DMARD & $59(65.56)$ & $216(64.48)$ & $0.849^{\mathrm{a}}$ \\
\hline MTX & $47(52.22)$ & $110(32.84)$ & $<0.001^{\mathrm{a}}$ \\
\hline Corticosteroids (oral only) & $13(14.44)$ & $335(100.00)$ & $<0.001^{\mathrm{a}}$ \\
\hline \multicolumn{4}{|l|}{ Pervious medication use } \\
\hline Biologic & $8(8.89)$ & $220(65.67)$ & $<0.001^{\mathrm{a}}$ \\
\hline DAS28-ESR, mean (SD) & $3.39(0.87)$ & $5.94(1.20)$ & $<0.001^{\mathrm{b}}$ \\
\hline
\end{tabular}

${ }^{a}$ Chi-squared test results. ${ }^{b} \mathrm{t}$ test results. ${ }^{\mathrm{c}}$ Concomitant use at any timepoint during the observation period including baseline. DAS28-ESR: Disease Activity Score based on 28-joint-erythrocyte sedimentation rate; DMARD: disease-modifying antirheumatic drugs; MTX: methotrexate. 
When TCZ is administered to patients with risk factors for serious infection, the benefits and risks of TCZ treatment should be thoroughly considered. Multivariate logistic regression analysis identified the following risk factors for serious infection: age $\geq 65$ years, longer disease duration ( $\geq$ $10 \mathrm{yrs}$ ), previous or concurrent respiratory disease, and mean concomitant corticosteroid dose $>5 \mathrm{mg} /$ day (prednisolone equivalent). The risk factors for serious infection identified in our study are similar to the findings reported from the all-patient PMS conducted for infliximab, etanercept, and adalimumab in Japan ${ }^{1,13,14,15}$. Patients with 3 or more of these risk factors had a cumulative incidence of serious infection about 10 times that of patients with no risk factors. TCZ should be used with caution in patients with these underlying risk factors. A limitation of our PMS study was the relatively short duration of followup; however, our data were rigorously collected, and the 28-week followup period should be sufficient to identify most serious infections.

In addition to serious infection, other $\mathrm{AE}$ were monitored in our study. For example, 39 cases of malignancy, including nonmelanoma skin cancer, were reported. However, no trends in cancer type were detected because this was a 28-week observational study; evaluation with longer-term data will be necessary to identify any trends. Anaphylaxis was reported in 10 patients. Most of the cases occurred within the first 3 infusions, indicating that careful monitoring for anaphylaxis is required during the early phase of TCZ treatment. Serious hepatic function disorders, due to the reactivation of the hepatitis virus, were not detected in our study. Nevertheless, TCZ treatment of patients infected with hepatitis virus (i.e., hepatitis virus carriers or patients with viral hepatitis) is not currently recommended because of limited experience with TCZ treatment in such patients. Additionally, because hepatitis B reactivation has been reported during treatment with other biologics, especially for anti-tumor necrosis factor therapy, careful screening and monitoring are also strongly recommended for patients given TCZ treatment ${ }^{15}$. In our study, the incidence rate of ILD $(0.5 \%)$ was equivalent to that found in the PMS of infliximab (0.5\%) and etanercept $(0.6 \%)$ in $\mathrm{Japan}^{1,13}$. Because infection could be a trigger for the onset of interstitial pneumonia, careful monitoring of infection will be important for patients with a concurrent or medical history of ILD. Overall, no safety issues were observed in our study that were not reported in previous clinical trials ${ }^{5,16}$

We also examined patient characteristics linked to successful TCZ treatment. Background factors shown to contribute to the achievement of Boolean-based remission, DAS28 remission, and EULAR Good Response in patients receiving TCZ included higher body weight ( $\geq 40 \mathrm{~kg}$ ), less advanced RA (Steinbrocker stage I+II or class $1+2$ ), no previous administration of biologics, no concomitant corticosteroids, no concomitant NSAID, and lower disease activity at baseline. There is a possibility that patients with body weight $<40 \mathrm{~kg}$ had a worse disease condition, and that this affected the results. Additionally, an analysis of factors contributing to the effectiveness of TCZ and serious infections demonstrated that patients with a shorter disease duration had a higher response rate and a lower risk for serious infections. The response rate was higher in patients with less advanced RA (e.g., stage I+II or class 1+2), and lower DAS28-ESR at baseline. These results indicate that it is preferable to start TCZ treatment in patients with less advanced RA, to maximize clinical response. Concomitant use of MTX positively affected the achievement of DAS28 remission and EULAR Good Response but not Boolean remission. There was a possibility that patients without concomitant use of MTX had reason to avoid using MTX (concurrent respiratory disease, for example) and that this caused the lower achievement of DAS28 remission and EULAR Good Response, compared with patients who received concomitant MTX. It is not clear whether concomitant use of MTX with TCZ is preferable to TCZ monotherapy.

Additionally, this TCZ PMS study is the first, to our knowledge, to depict a benefit-risk balance for biologic DMARD. To assess the benefit-risk balance of TCZ treatment, the scatter plot of the predicted probability of developing serious infection versus the predicted probability of achieving Boolean-based remission was derived from the logistic models, and divided into 9 groups (Figure 2). These analyses revealed that higher predicted probabilities of achieving Boolean-based remission tended to be associated with lower predicted probabilities of developing serious infection; likewise, higher predicted probabilities of developing serious infection tended to be associated with lower predicted probabilities of achieving Boolean-based remission.

Because this study was limited by the absence of a control group and by having only a 28 -week observation period, it will be necessary to confirm the results of this benefit-risk analysis using each individual cohort. Moreover, identification and use of new biomarkers that can increase the accuracy of these predictions may allow for the more precise calculation of an individual patient's benefit-risk balance.

When selecting appropriate treatments for patients with $\mathrm{RA}$, it is preferable to treat those patients with a higher probability of remission and a lower predicted probability of developing serious adverse drug reactions, such as serious infections with TCZ. From the results of the Japanese PMS presented here, initiating TCZ treatment in patients with less advanced RA is preferable to achieve the best outcomes for these patients.

\section{ACKNOWLEDGMENT}

The authors thank all investigators for their contributions to the implementation of our study. Support for third-party writing assistance for this manuscript was provided by F. Hoffmann-La Roche Ltd. 


\section{REFERENCES}

1. Koike T, Harigai M, Inokuma S, Ishiguro N, Ryu J, Takeuchi T, et al. Postmarketing surveillance of tocilizumab for rheumatoid arthritis in Japan: interim analysis of 3881 patients. Ann Rheum Dis 2011;70:2148-51.

2. Koike R, Harigai M, Atsumi T, Amano K, Kawai S, Saito K, et al. Japan College of Rheumatology 2009 guidelines for the use of tocilizumab, a humanized anti-interleukin-6 receptor monoclonal antibody, in rheumatoid arthritis. Mod Rheumatol 2009;19:351-7.

3. van Gestel AM, Prevoo ML, van 't Hof MA, van Rijswijk MH, van de Putte LB, van Riel PL. Development and validation of the European League Against Rheumatism response criteria for rheumatoid arthritis. Comparison with the preliminary American College of Rheumatology and the World Health Organization/International League Against Rheumatism Criteria. Arthritis Rheum 1996;39:34-40.

4. Nakajima A, Inoue E, Tanaka E, Singh G, Sato E, Hoshi D, et al. Mortality and cause of death in Japanese patients with rheumatoid arthritis based on a large observational cohort, IORRA. Scand J Rheumatol 2010;39:360-7.

5. Nishimoto N, Ito K, Takagi N. Safety and efficacy profiles of tocilizumab monotherapy in Japanese patients with rheumatoid arthritis: meta-analysis of six initial trials and five long-term extensions. Mod Rheumatol 2010;20:222-32.

6. Nishimoto N, Miyasaka N, Yamamoto K, Kawai S, Takeuchi T, Azuma J, et al. Study of active controlled tocilizumab monotherapy for rheumatoid arthritis patients with an inadequate response to methotrexate (SATORI): significant reduction in disease activity and serum vascular endothelial growth factor by IL-6 receptor inhibition therapy. Mod Rheumatol 2009;19:12-9.

7. Nishimoto N, Hashimoto J, Miyasaka N, Yamamoto K, Kawai S, Takeuchi T, et al. Study of active controlled monotherapy used for rheumatoid arthritis, an IL-6 inhibitor (SAMURAI): evidence of clinical and radiographic benefit from an $\mathrm{x}$ ray reader-blinded randomised controlled trial of tocilizumab. Ann Rheum Dis 2007;66:1162-7.

8. Nishimoto N, Miyasaka N, Yamamoto K, Kawai S, Takeuchi T, Azuma J. Long-term safety and efficacy of tocilizumab, an anti-IL-6 receptor monoclonal antibody, in monotherapy, in patients with rheumatoid arthritis (the STREAM study): evidence of safety and efficacy in a 5-year extension study. Ann Rheum Dis 2009;68:1580-4.
9. Smolen JS, Beaulieu A, Rubbert-Roth A, Ramos-Remus C, Rovensky J, Alecock E, et al. Effect of interleukin-6 receptor inhibition with tocilizumab in patients with rheumatoid arthritis (OPTION study): a double-blind, placebo-controlled, randomised trial. Lancet 2008;371:987-97.

10. Genovese MC, McKay JD, Nasonov EL, Mysler EF, da Silva NA, Alecock E, et al. Interleukin-6 receptor inhibition with tocilizumab reduces disease activity in rheumatoid arthritis with inadequate response to disease-modifying antirheumatic drugs: the tocilizumab in combination with traditional disease-modifying antirheumatic drug therapy study. Arthritis Rheum 2008;58:2968-80.

11. Jones G, Sebba A, Gu J, Lowenstein MB, Calvo A, Gomez-Reino $\mathrm{JJ}$, et al. Comparison of tocilizumab monotherapy versus methotrexate monotherapy in patients with moderate to severe rheumatoid arthritis: the AMBITION study. Ann Rheum Dis 2010;69:88-96.

12. Emery P, Keystone E, Tony HP, Cantagrel A, van Vollenhoven R, Sanchez A, et al. IL-6 receptor inhibition with tocilizumab improves treatment outcomes in patients with rheumatoid arthritis refractory to anti-tumour necrosis factor biologicals: results from a 24-week multicentre randomised placebo-controlled trial. Ann Rheum Dis 2008;67:1516-23.

13. Takeuchi T, Tatsuki Y, Nogami Y, Ishiguro N, Tanaka Y, Yamanaka $\mathrm{H}$, et al. Postmarketing surveillance of the safety profile of infliximab in 5000 Japanese patients with rheumatoid arthritis. Ann Rheum Dis 2008;67:189-94.

14. Koike T, Harigai M, Inokuma S, Ishiguro N, Ryu J, Takeuchi T, et al. Postmarketing surveillance of safety and effectiveness of etanercept in Japanese patients with rheumatoid arthritis. Mod Rheumatol 2011;21:343-51.

15. Koike T, Harigai M, Inokuma S, Inoue K, Ishiguro N, Ryu J, et al. Postmarketing surveillance of the safety and effectiveness of etanercept in Japan. J Rheumatol 2009;36:898-906.

16. Schiff MH, Kremer JM, Jahreis A, Vernon E, Isaacs JD, van Vollenhoven RF. Integrated safety in tocilizumab clinical trials. Arthritis Res Ther 2011;13:R141. 